essential. We hope that our future work attracts similar attention-bad publicity is better than no publicity at all.

Burns, A., Reith, M., Levy, R., el al (1990a) "How to do it"obtaining consent for autopsy in Alzheimer's disease. International Journal of Geriatric Psychiatry, 5, 183-286.

- , LUTHERT, P., LEVY, R., et al (1990b) Accuracy of clinical diagnosis of Alzheimer's disease. British Medical Journal, 301 1026.

Chui, H. C., Victoroff, J. I., MARgolin, D., el al (1992) Criteria for the diagnosis of ischemic vascular dementia proposed by the State of California Alzheimer's Disease Diagnostic and Treatmen Centers. Neurology, 42, 473-480.

Homer, A., Honovar, M., Lantos, P., el al (1988) Diagnosing dementia: do we get it right? British Medical Journal, 297, 894-896.

Perry, R., Irving, D., Blessed, G., et al (1989) A clinically and neuropathologically distant form of dementia in the elderly. Lancet, $i, 166$.

Roman, G. C., Tatemichi, T. K. Erkinjunttr, T. et al (1993) Vascular dementia: diagnostic criteria for Research Studies Report of the NINDS-AIREN International Workshop. Neurology, 43, 250-260.

University of Manchester

Department of Old Age Psychiatry

Withington Hospital

Manchester M208LR

Institute of Psychiatry

RAYMOND LEVY

De Crespigny Park

Denmark Hill

London SE5 8AF

SIR: The article by Dr Brayne (Journal, April 1993, $162,439-446)$ concentrates on dementia in the general population but fails to discuss recent findings and recommendations as applied to the largest single group of people who develop Alzheimer's dementia; that is people with Down's syndrome. Difficulties inherent in the application of standard criteria (CAMDEX, DSM-III-R, NINCDS-ADRDA) in people with a learning disability have not been adequately investigated. Such definitions and criteria are difficult to apply to this population when falsepositive diagnoses may occur due to difficulty in testing (due to sensory handicap or loss, poor cooperation with testing), confounding illnesses being present (e.g. thyroid disorder), and also due to lack of knowledge of the ageing process in older people with Down's syndrome.

A greater emphasis can be placed on behavioural and neurological changes as these are often valuable in the diagnosis of dementia (Lai \& Williams, 1989; Evenhuis, 1990). Serial changes in behaviour over time in people with Down's syndrome may be used to support the clinical diagnosis of dementia (Prasher et al, 1993).

The relationship between clinical measurements and post-mortem findings must remain controversial as such findings may not necessarily correlate, as is the case with people with Down's syndrome. Virtually all people over the age of $\mathbf{4 0}$ years have neuropathological changes of Alzheimer's dementia, but not all will have changes of clinical dementia (Lai \& Williams, 1989).

Evenhuis, H. M. (1990) The natural history of dementia in Down's syndrome. Archives of Neurology, 47, 263-267.

LAI, F. \& WILLIAMS, R.S. (1989) A prospective study of Alzheimer's disease in Down's syndrome. Archives of Neurology, 46, 849-853.

Prasher, V. P., Krishinan, V. H. R., Clarke, D. J., et al (1993) The assessment of dementia in people with Down's syndrome; changes in adaptive behaviour. British Journal of Developmental Disability (in press).

V. Prasher

V. H. R. KRISHNAN

Queen Elizabeth Psychiatric Hospital

Mindelsohn Way

Birmingham B15 2QZ

\section{Lewy bodies and Alzheimer's disease}

SIR: Förstl et al (Journal, March 1993, 162, 385-392) have described the clinical characteristics of eight patients meeting NINCDS criteria for Alzheimer's disease but subsequently showing cortical Lewy bodies at autopsy. Although we agree that a signifcant number of patients meeting existing clinical diagnostic criteria for Alzheimer's disease will have Lewy body pathology, our own experience is that such patients are not representative of the clinical presentations more typically associated with cortical Lewy body disease.

Förstl et al report that the "Lewy body variant" patients in their sample were clinically no different from those without Lewy bodies, except for an increase in rigidity developing during the course of illness. This is surely an inevitable consequence of the case selection bias, only patients fulfilling NINCDS clinical criteria having been selected for study and those with other psychiatric presentations excluded. Our experience of $\mathbf{4 1}$ autopsy-confirmed cases of Lewy body dementia (McKeith et al, 1992a, 1992b) is that $80 \%$ present with a syndrome of fluctuating $\operatorname{cog}$ nitive impairment associated with hallucinations (usually visual), and with Parkinsonian features which are often precipitated by neuroleptics. A minority $(10-15 \%)$ of Lewy body patients lack this fluctuating picture and are therefore similar to those described by Förstl et al. A further 5-10\% present 